\title{
Bezerra da Silva, Cartola \& Velha Guarda da Portela: um mergulho no documentário brasileiro contemporâneo sobre samba
}

\author{
Guilherme Carréra Campos Leal*
}

Resumo: O presente artigo propõe uma análise dos documentários Onde a coruja dorme (2012), de Márcia Derraik e Simplício Neto; Cartola - música para os olhos (2006), de Lírio Ferreira e Hilton Lacerda e O mistério do samba (2008), de Carolina Jabor e Lula Buarque de Hollanda, a fim de investigar como o documentário brasileiro contemporâneo trabalha temas caros ao universo do samba, a partir de personalidades pertencentes a esse mesmo universo.

Palavras-chave: documentário; cinema brasileiro; samba; representação.

Resumen: El presente artículo propone un análisis de los documentales Onde a coruja dorme (2012), de Márcia Derraik y Simplício Neto; Cartola - música para os olhos (2006), de Lírio Ferreira y Hilton Lacerda y O mistério do samba (2008), de Carolina Jabor y Lula Buarque de Hollanda, a fin de investigar cómo el documental brasileño contemporáneo trabaja temas caros al universo de la samba, a partir de personalidades pertenecientes a ese mismo universo.

Palabras clave: documental; cine brasileño; samba; representación.

\begin{abstract}
This article aims to analyse documentaries Onde a coruja dorme (2012), by Márcia Derraik e Simplício Neto; Cartola - música para os olhos (2006), by Lírio Ferreira e Hilton Lacerda and $O$ mistério do samba (2008), by Carolina Jabor e Lula Buarque de Hollanda, in order to investigate how the contemporary Brazilian documentary deals with themes attached to the realm of samba, through important musicians linked to this same milieu.

Keywords: documentary; Brazilian cinema; samba; representation.
\end{abstract}

Résumé : Cet article propose une analyse des documentaires Onde a coruja dorme (2012), de Márcia Derraik e Simplício Neto; Cartola - música para os olhos (2006), de Lírio Ferreira e Hilton Lacerda et $O$ mistério do samba (2008), de Carolina Jabor e Lula Buarque de Hollanda, afin d'étudier comment le documentaire brésilien contemporain aborde les thèmes de l'univers de la samba, en prenant en compte que ces films sont réalisés par des personnes appartenant au même monde.

Mots-clés : documentaire ; cinema brésilien ; samba ; répresentation.

* Doutorando. University of Westminster, School of Media Arts and Design, Centre for Research and Education in Arts and Media. Bolsa Capes. W1B 2HW, Londres, Reino Unido. E-mail: guilhermecarrera@gmail.com

Submissão do artigo: 25 de maio de 2017. Notificação de aceitação: 13 de julho de 2017. 
Bezerra da Silva, Cartola \& Velha Guarda da Portela: um mergulho no documentário brasileiro contemporâneo sobre samba

Desde o fim da década de 1990, o documentário brasileiro vem assumindo lugar de destaque na cinematografia nacional. Não apenas pelas leis de incentivo que ajudaram a produção a se reerguer das cinzas devido ao fechamento da Embrafilme pelo então presidente Fernando Collor de Mello, mas, sobretudo, pelas vantagens advindas da tecnologia digital que permitiriam cineastas, consagrados e iniciantes, arriscarem em linguagem, tema e abordagem (Lins \& Mesquita, 2011). Entre a consolidação da fase madura do cinema de Eduardo Coutinho (seus dispositivos, entrevistas e personagens) e a problematização mais acentuada das fronteiras do gênero em si (desde Um passaporte húngaro, de Sandra Kogut, passando por Serras da desordem, de Andrea Tonacci, chegando ao próprio Coutinho em Jogo de cena), o documentário musical atingiu seu ápice no século XXI. Ainda que o cinema brasileiro tenha se alimentado da música (em particular, do Samba) para se sustentar na primeira metade do século XX (dos registros dos desfiles carnavalescos às chanchadas inegavelmente musicais), é no documentário contemporâneo que figuras ilustres ganham perfis audiovisuais à altura de suas representatividades no âmbito cultural. Neste artigo, propomos um mergulho nos longas-metragens Onde a coruja dorme (2012), de Márcia Derraik e Simplício Neto, Cartola - Música para os olhos (2006), de Lírio Ferreira e Hilton Lacerda, e O mistério do Samba (2008), de Carolina Jabor e Lula Buarque de Hollanda. Assim como os filmes em questão, nossa investida parte dos personagens enquadrados (Bezerra da Silva, Cartola e a Velha Guarda da Portela, respectivamente), para trabalhar temas caros ao universo do Samba. Nesse sentido, dividimos as três seções subsequentes por tópicos que se deixam perceber em cada um desses documentários. Não à toa, esses tópicos podem também ser embaralhados e assim surgir no documentário vizinho. Todos eles, no entanto, apresentam de antemão a necessidade maior de se pôr luz sobre o Samba, esse gênero musical que surgiu nas dobras da sociedade para se impor como símbolo da identidade brasileira.

\section{O malandro e a macumba}

A história de José Bezerra da Silva não é o mote principal de Onde a coruja dorme, documentário de 72 minutos, dirigido por Márcia Derraik e Simplício Neto. Embora sua trajetória do Recife ao Rio de Janeiro, e do Rio de Janeiro ao estrelato, merecesse mais atenção, é o Samba cantado por Bezerra da Silva o verdadeiro protagonista. O estrelato ao qual nos referimos não é, no entanto, sinônimo de mainstream, já que o sucesso desse pernambucano em terras fluminenses se manteve à margem do star system da produção fonográfica. Embora tenha gravado seu primeiro disco em 1969, foi com a participação em Partido-alto nota $10 \mathrm{vol}$. 2, no ano de 1978, que se destacou com a música 
Pega que eu sou ladrão. Por conta disso, no ano seguinte, fechou contrato com a gravadora RCA Victor, onde permaneceu por 14 anos, e onde lançou seus maiores êxitos comerciais, como o LP Produto do morro, no qual canta a clássica Minha sogra. Nascido em 1927 e morto em 2005, Bezerra da Silva esteve no mundo, portanto, desde o surgimento do Samba urbano, no fim da década de 1920, início da década de 1930, passando pela consolidação da cultura do carnaval, das escolas de Samba, dos desfiles carnavalescos, até a transformação pela qual o partido-alto passou, rumo a um diálogo com outros estilos musicais, chegando até o pagode romântico (Trotta, 2011). Nesse sentido, afirmar que Bezerra da Silva corporifica a história do Samba significa dizer também que ele corporifica a tensão inerente a essa história. Onde a coruja dorme, coprodução da TvZERo, Antenna e Teleimage, investiga essa tensão, muito fincado no presente, mas criando conexões com o passado, a todo instante.

Para o mercado da música, Bezerra da Silva foi enquadrado como esse sujeito periférico, contestador, inquieto. Um legítimo representante do instinto do morro, em particular, do Cantagalo, na Zona Sul do Rio de Janeiro. "Eu sou o porta-voz", afirma para a câmera. E é o porta-voz porque acredita que o morro não teria voz, se assim não fosse. Seria sempre atacado, sem saber se defender. "Marginal, ladrão, safado...", os xingamentos que o morro se acostumou a ouvir, elenca o cantor. A presença da polícia se dá nas primeiras imagens do filme. Armadas, as figuras dos policiais contrastam com os sorrisos dos jovens moradores do morro. A trilha sonora é Se não fosse o Samba, cuja letra de 1989 denuncia: "E toda vez que descia o meu Morro do Galo/Eu tomava uma dura/Os homens voavam na minha cintura/Pensando encontrar aquele três oitão". A vigília, muitas vezes seguida de punição, não é novidade para o morro. Nem para o Samba feito no morro. É sua tensão primeira. Aquela que resulta de uma divisa entre morro e asfalto, onde a geografia rege (ou obedece) as relações sociais. Essa divisa simboliza uma ruptura dentro da sociedade que nunca foi sanada, embora venha sendo assistida. O Samba, ou melhor, a repressão ao Samba é apenas um dos sintomas dessa ruptura. A vigília e a punição cantadas por Bezerra da Silva, sabemos, vêm desde a Praça Onze, quando a polícia já cumpria a função de reprimir os primeiros sambistas, acusados de desordeiros. Do Bota-abaixo do prefeito Pereira Passos (1902-1906) à instalação de Unidades de Polícia Pacificadora (UPP) no século XXI, a cidade do Rio de Janeiro esteve sempre sitiada. As mudanças urbanísticas destrinchadas por Carlos Sandroni (2001), entre outros autores, não deixam escapar as mudanças sociais que aconteciam em paralelo. Ex-escravos, imigrantes nordestinos, operários fluminenses, esses e outros grupos considerados marginais pela elite carioca se encontrariam no morro. E, como consequência, encontrariam tam- 
Bezerra da Silva, Cartola \& Velha Guarda da Portela: um mergulho no documentário brasileiro contemporâneo sobre samba

bém uma outra realidade, responsável pelo imaginário que se construiria. Essa realidade é o combustível das composições gravadas por Bezerra da Silva. É ele, ainda, o homem por trás desse imaginário idealizado para o morro, presente no Samba.

Nesse sentido, a preocupação de Onde a coruja dorme, como se uma extensão da preocupação do sambista, está em dar voz a quem vivencia esse morro. Bezerra da Silva diz cantar aquilo que quem ali vive escreve, comenta, pede. São eles: Popular P, Adelzonilton, Edson Show, Roxinho, Pedro Butina, Pinga, Tião Miranda, Claudinho Inspiração, 1000tinho, entre outros moradores-compositores gravados pelo intérprete. Ele canta o trabalhador que acorda às $3 \mathrm{~h}$ da madrugada, pega o ônibus às $4 \mathrm{~h}$, já levando a marmita para $\mathrm{o}$ almoço. "Malandro quer dizer inteligência", traduz. No documentário, vamos conhecendo esses trabalhadores, envolvidos com o Samba, mas que vivem independentemente dele, em suas profissões cotidianas. Eletricista, bombeiro, marceneiro. "Malandro usa a consciência. Bandido é a mão no revólver", explica 1000tinho. Essa diferenciação é mais do que o argumento de Se não fosse o Samba, entre outras tantas músicas, é uma defesa oral. Sandroni (2001) vai trabalhar a ideia de que Samba e malandro sempre estiveram associados, desde a virada dos anos 1920 para os 1930, uma vez que "tal associação será feita pelo senso comum, pela imprensa do Rio de Janeiro e pelas próprias letras das canções" (Sandroni, 2001: 156). Há, no entanto, uma diferença entre o que Sandroni entende por malandragem e o que Bezerra da Silva canta em seus três milhões de discos vendidos em 28 álbuns lançados. Não se trata de uma discordância, mas de perspectivas históricas distintas. Enquanto o primeiro conceitualiza malandragem a partir do contexto dos anos 1930, o segundo tem como parâmetro a sociedade das últimas décadas do século XX. A abordagem relacionada ao trabalho, portanto, vai diferir.

Enquanto o músico defende o malandro como aquele que trabalha (acorda às $3 \mathrm{~h}$, pega o ônibus às $4 \mathrm{~h}$ ), o teórico desenvolve uma argumentação sobre a esquiva. “(...) Trabalha o mínimo possível, vive do jogo, das mulheres que o sustentam e dos golpes que aplica nos otários" (Sandroni, 2001: 156). Assim como em relação à origem musical, essa figura do malandro também teria sido herdada de ritmos antecessores ao Samba. Ou seja, do lundu ao maxixe, o malandro, antes chamado vadio, conciliava viola e bebida como seus, digamos, instrumentos de trabalho. É na década do nascimento de Bezerra da Silva que o malandro passa a remeter ao Samba, àquele Samba urbano que se instalava. A análise de Sandroni (2001) vai ressaltar ainda que esse estereótipo malandro marca presença nas próprias criações dos compositores, sobretudo dos anos 1930 em diante. Mais do que uma escolha, a posição do malandro in- 
tegra um imaginário. A ser problematizado nas letras da geração subsequente, aquela de Bezerra da Silva. É do interesse de quem associar sambista à malandragem? Ou, melhor dizendo, associar malandragem a periféricos, pobres, negros? Bezerra da Silva não nega sua origem, nem quer fazer do morador do morro um indivíduo alheio à roda de Samba. Mas seu malandro trabalha. Para se sustentar e para sustentar um discurso contrário àquele do passado. Em determinado momento, o músico contemporiza a importância, inclusive, das Velhas Guardas. Critica a tradição e talvez nessa tradição ele inclua a imagem desse malandro preguiçoso, por ele deposto.

Outra imagem frequentemente associada ao universo do Samba é a da macumba. Embora considerada uma herança africana, a macumba, na verdade, é um termo genérico empregado para designar manifestações religiosas diversas, sempre enfatizando uma relação mediúnica. O próprio título do livro de Sandroni (2001) faz menção a essa seara: Feitiço decente. O autor, inclusive, se atém a esse jogo de palavras. Retoma Noel Rosa, com a letra Feitiço da Vila, composta em 1934. "Esta palavra é usada no Brasil também para designar as oferendas deixadas nas encruzilhadas com finalidades mágicas, geralmente no quadro das religiões afro-brasileiras" (Sandroni, 2001: 171). O feitiço da oferenda passa a ser também o feitiço do Samba, no momento em que este, enfim, alcança sua aceitação social. Sandroni (2001) conclui: "A doce vingança dos negros libertos é produzir uma música que escraviza quem a escuta: decente, porém feitiço" (2001: 171). Do terreiro fundante de Tia Ciata ao dia-a-dia no morro, o feitiço, a oferenda e a macumba foram se infiltrando. Concomitantemente, o preconceito. Em Onde a coruja dorme, Bezerra da Silva se posiciona: "Quando o camarada é preto, feio, analfabeto e mora longe, é macumbeiro; quando é branco de olhos azuis, é espiritualista". Enquanto ouvimos exemplos de canções que contemplam o tema, velas acesas, imagens de santos e flores espalhadas tomam a tela. O entrevistado Wilsinho Saravá lembra que a relação entre Samba e macumba é profícua. A macumba, assim como a imagem do malandro, antes chamado de vadio, é anterior ao morro, vem das senzalas. São assuntos apontados no presente do registro audiovisual, mas que estão ecoando do passado.

Ex-chefe da Polícia Civil do Rio de Janeiro, Hélio Luz é um dos que comentam o significado atribuído ao morro hoje, bem como o que representam seus moradores. Em sua análise, não há como dissociar a história do morro e de quem nele vive da história da escravidão no Brasil. Escravos e ex-escravos vindos da África diretamente para a capital federal - "só entre 1852 e 1859 os tráficos interprovincial e intermunicipal traziam, a cada ano, cerca de 5.500 escravos para a província fluminense" (Lopes, 2008: 38) - ou escravos e ex- 
Bezerra da Silva, Cartola \& Velha Guarda da Portela: um mergulho no documentário brasileiro contemporâneo sobre samba

escravos imigrantes do Nordeste do país - quando a região "sofre os efeitos da maior seca de sua história", faz com que "enormes contingentes de escravos sejam vendidos para os grandes centros" (Lopes, 2008: 38) - povoaram o centro do Rio de Janeiro, passando pela zona portuária, chegando aos subúrbios. A favela, essa instituição geográfica, urbanística e arquitetônica brasileira, sobretudo carioca, serviu ao encontro desses escravos e ex-escravos expulsos de suas casas, desamparados pelo governo brasileiro após a libertação. Em determinado momento, quando Onde a coruja dorme investe na problematização do papel da elite no tráfico de drogas no Rio de Janeiro, Hélio Luz faz a comparação: "Eles ligam o narcotráfico à senzala moderna, que é a favela [grifo nosso]", para depois prosseguir questionando a criminalidade como algo inerente ao morro. Sabemos, essa senzala moderna se apresenta como desdobramento da situação em que se encontravam os antigos moradores das reais senzalas, depois de serem expulsos de seus cortiços compartilhados. A herança africana subiu o morro e o maior legado desse movimento tão injusto quanto frutífero é o nascimento do Samba carioca.

\section{O intertexto e a hierarquia}

A abordagem de Lírio Ferreira e Hilton Lacerda sobre vida e obra de Angenor de Oliveira, mais conhecido como Cartola, diferencia o documentário da dupla dos de seus contemporâneos. Da Raccord Produções, Cartola - Música para os olhos consegue adicionar novos elementos ao documentário musical brasileiro. Além dos depoimentos, das imagens de arquivo, dos números musicais, da observação de um cotidiano e da intervenção mínima nesse cotidiano, características em comum nos filmes selecionados, este incorpora outras duas frentes narrativas. Ao longo de seus 88 minutos, 34 filmes aparecem em trechos na tela, entre curtas e longas, ficção e não ficção, como se em um imenso intertexto. A lista vai de O que foi o carnaval de 1920? (1920), de Alberto Botelho, ainda nos tempos do cinema silencioso, até Rio Zona Norte (1957), do cinemanovista Nelson Pereira dos Santos. Esses trechos vão sendo admitidos no roteiro, sem cerimônia. Não há crédito enquanto são exibidos, são listados apenas ao fim da sessão. De modo que não criam uma separação entre o que é Cartola e o que é determinado filme. Perde-se a fronteira, tanto entre ficção e não ficção, como entre documentários. Ganha a narrativa em inventividade, como acontece a exemplo da sequência inicial.

Partimos do documentário de Aloysio Raolino sobre o enterro de Cartola, A morte de um poeta (1981), cujas imagens são cobertas pela canção Divina dama, na voz do próprio perfilado. "Tudo acabado/E o baile encerrado/Atordoado fiquei”. Em seguida, chegamos a Brás Cubas (1985), a incur- 
são oitentista de Júlio Bressane pela obra-prima do escritor Machado de Assis. $\mathrm{O}$ áudio que cobre a imagem de um esqueleto nebuloso recortado do filme é a narração de Jards Macalé, recitando as primeiras linhas do livro lançado em 1881. "Algum tempo hesitei se devia abrir estas memórias pelo princípio ou pelo fim, isto é, se poria em primeiro lugar o meu nascimento ou a minha morte". A escolha por essa espécie de prólogo evidencia que, assim como em Memórias póstumas de Brás Cubas, Ferreira e Lacerda resolveram começar pelo fim de Cartola, sua morte. Mais do que isso, esse prólogo funciona como um comentário extra ao filme. "Machado, que foi menino pobre, saiu de um gueto para se tornar o maior escritor brasileiro, representando uma tradição culta. Já Cartola teve uma infância burguesa e, aos 11 anos, sua vida mudou, foi morar numa comunidade pobre e se tornou o maior representante da cultura popular brasileira", explica Lacerda em entrevista a Luiz Fernando Vianna (Folha de S. Paulo, 2007). Essa relação é construída pelo filme a partir de uma "coincidência cabalística", como coloca Ferreira na mesma entrevista: Machado morre em 1908, mesmo ano em que Cartola nasce. Do nascimento à infância, o documentário sugere outro elemento narrativo, para além dos extratos dos longas-metragens ficcionais. Um Cartola menino perambula por entre os frames, despertando curiosidade no espectador. Marcos Paulo Simião é o ator mirim que veste a indumentária do perfilado. Em nenhum momento, no entanto, é dito que o mesmo interpreta o sambista. Da mesma forma em que Ferreira e Lacerda não explicam a passagem de um trecho de filme para outro, a presença da criança passa incólume a didatismo. Sua participação evoca a ideia do sambista original, primeiro. E isso basta à narrativa. "Eu comecei a me interessar pelo Samba desde que eu me mudei pra Mangueira, com 11 anos", conta Cartola, o cantor, em depoimento, enquanto Cartola, o menino, passeia pela estação ferroviária. $\mathrm{O}$ figurino de chapéu, terno e gravata aproxima ainda mais o cantor do menino.

Depois que subiu o morro da Mangueira, não só conheceu o Samba, como passou a produzi-lo. O interesse e a dedicação o levaram a fundar o Bloco dos Arengueiros, ao lado do amigo Carlos Cachaça, em 1925. Três anos depois, nascia o Grêmio Recreativo Escola de Samba Estação Primeira de Mangueira, como resultado da união dos blocos congêneres do entorno. Chega de demanda, composto naquele mesmo ano, seria escolhido o Samba do primeiro desfile da Verde e Rosa. Curiosamente, só seria gravado por Cartola na década de 1970 para o LP História das escolas de Samba: Mangueira. Com o desenvolvimento das rádios nacionais, sabemos que a indústria fonográfica crescia avassaladoramente. Com a consolidação do Samba no imaginário brasileiro, sabemos também que essa mesma indústria fonográfica escanteava os sambis- 
Bezerra da Silva, Cartola \& Velha Guarda da Portela: um mergulho no documentário brasileiro contemporâneo sobre samba

tas, privilegiando os célebres cantores do mercado. A relação entre compositor, sambistas como Cartola, e produtor musical, responsáveis por angariar letra e melodia para suas estrelas gravarem, marca a problemática do gênero musical. Dos livros aos filmes, a compra e a venda de Sambas não passam em branco. Em Cartola, a montagem destaca esse contato. Expõe o depoimento do sambista sobre sua experiência particular, enquanto cenas do clássico pré-Cinema Novo Rio Zona Norte (1957) ilustram o ocorrido: Jece Valadão faz uma oferta a Grande Otelo, em uma interação ficcional, porém verdadeira. A celeuma também se torna assunto em Onde a coruja dorme. "Você sabe quantos milhões de discos eu vendia? Sabe quanto eu recebi? Aí é que tá o problema!", queixa-se Bezerra da Silva. "Sabe o que significa ECAD? Cadê", brinca 000tinho. "Assinou, tem até que tomar cuidado pra o cheque não fazer um 's' e dizer o contrário", avisa Tião Miranda. Nesses depoimentos, vão além. Não retomam apenas a compra e venda que acontecia às margens do profissionalismo da primeira metade do século XXI. A crítica sobre o ECAD é contemporânea. Órgão responsável por calcular quanto deve ser pago pelos usuários de música, o Escritório Central de Arrecadação de Direitos Autores é duramente atingido na fala do sambista. Bezerra da Silva cita, inclusive, a gravadora BMG. A certa altura, enquanto fala ao telefone, a câmera registra: "Eles são ladrões. (...) Roubam mesmo, não pagam ninguém”.

Essa relação hierárquica entre o empresariado e o sambista nos remete a uma outra complexa parceria. Para o encontro entre a elite intelectual e os músicos populares, Hermano Vianna (2010) deu o merecido destaque em seu tratado acadêmico. É dessa cumplicidade, nunca livre de tensões, que o Samba parece ganhar molde, no Rio de Janeiro dos anos 1920 e 1930. Uma das críticas do autor se dirige justamente aos que preferem fingir que essa interação não acontecia. "Por que dizer que nossos músicos populares eram simplesmente reprimidos ou desprezados pela elite brasileira?" (Vianna, 2010: 47). O teórico sai do livro à tela ao fazer uma aparição em Cartola. "Existia uma preocupação naquela época com o que era o Brasill”: sua afirmação diante da câmera não nos deixa esquecer a base de sua pesquisa. Vianna (2010) investiga essa repressão, interação, relação, a fim de compreender o que se resolve chamar de Brasil, após a Proclamação da República em 1889. "Nós temos a capacidade de representar os brasileiros", completa Nelson da Nóbrega, ainda em testemunho a Ferreira e Lacerda. É a frase que complementa, portanto, a premissa de Vianna (2010). O "nós" em questão não diz respeito a nenhum dos dois autores, mas aos músicos populares, em detrimento da elite intelectual. Entre repressão e interação, sobraram características particulares a cada um dos dois grupos sociais. O elogio à informalidade talvez demarque a primeira notável 
diferença entre ambos. "Se você foi pra escola, estudou, se formou, aprendeu, tudo bem. Vamos bater palmas, né? Mas o outro fazer a mesma coisa que você sem ir a lugar nenhum...", compara Bezerra da Silva. O outro, claro, é ele mesmo. É também Cartola. São os moradores do morro. São os músicos populares dos anos 1920 e 1930. O depoimento do compositor Elton Medeiros exemplifica essa informalidade. O filme é Cartola, mas poderia ser qualquer outro. Ele conta em tom prosaico sobre a visita que fez ao amigo Angenor. Começaram a conversar, resolveram fazer um Samba. Cartola pegou o violão, fez sua parte. Com a chegada de Renato Agostini, os dois quiseram tocar o Samba que tinha acabado de vir ao mundo. Agostini não acreditou na história e pediu para assistir ao parto de uma outra composição, sendo testemunha ocular. "Em 40 minutos, essa música tava pronta": "A sorrir/Eu pretendo levar a vida/Pois chorando/Eu vi a mocidade perdida".

\section{O manuscrito e a mulher}

As composições, sabemos, eram criadas, em sua maioria, por sambistas analfabetos ou semianalfabetos. Integrante da Velha Guarda da Portela, a seleta ala de sambistas de uma das mais tradicionais escolas de Samba do Rio de Janeiro (Vargens e Monte, 2004), a dúvida em Argemiro começa em relação à pronúncia. Não sabe se a palavra "âmbito" se pronuncia como se escreve, "âmbito", ou sem o acento gráfico, "ambito". Ironicamente, quem põe fim ao impasse é alguém da equipe de filmagem. A voz vinda do fora de quadro é ouvida pelo espectador: "É âmbito", ensina. Em Oswaldo Cruz, sede da Portela na Zona Norte do Rio de Janeiro, uma possível hierarquia se repete no esclarecimento. Em seguida, Argemiro ainda pergunta: "O que é que quer dizer isso?". O registro é válido como forma de nos lembrar certa limitação, mas não impede a ode a letras que se tornaram clássicos do cancioneiro nacional. No documentário em questão, $O$ mistério do Samba, dirigido por Carolina Jabor e Lula Buarque de Hollanda e sob produção da Conspiração Filmes, Phonomotor e Natura, vemos a cantora Marisa Monte chegar à casa de Dona Neném, viúva de Manacéa, antigo sambista da Portela. Marisa, o filme já nos explicou, está fazendo um trabalho de resgate dos Sambas da Velha Guarda. Esse projeto sonoro ganhou voz em Tudo azul, álbum por ela produzido, lançado em 2000 pela gravadora EMI (Marisa Monte, 2014). As imagens gravadas durante esse processo serviram de base para o documentário de Jabor e Hollanda, cujo objetivo é fazer um retrato dessa instituição chamada Velha Guarda da Portela. De volta à sequência, a cantora cumprimenta a matriarca, cumprimenta Áurea Maria, filha do casal. Em conversa, pergunta sobre a relação de ambas com o Samba. Áurea conta que, quando criança, ela e outros colegas, eram chamados 
Bezerra da Silva, Cartola \& Velha Guarda da Portela: um mergulho no documentário brasileiro contemporâneo sobre samba

pelo pai e seus parceiros compositores, para memorizar aquilo que eles tinham acabado de criar. Eram como gravadores humanos. Outra prova da informalidade da música que ali era feita. "Ele não tinha caderno?". Tinha, mas a mãe emprestou a um jornalista, que nunca mais o devolveu. Mais adiante, Marisa tem acesso a uma maleta de Manacéa, entregue pela viúva. Juntas, procuram por composições esquecidas em velhos pedaços de papel. Encontram o manuscrito de Volta. Além de ratificar o esforço de pesquisa empreendido pela cantora, sobre o qual o documentário joga luz, a sequência acentua a qualidade dos versos. Na cena seguinte, toda a quadra da Portela canta Volta. Antes, esquecido. Agora, midiatizado.

Volta (Manacéa)

Meu bem, por que estás assim tão triste?

Alguma coisa em você existe

A tristeza, amor, só nos causa dor

Volta, vem cantar, para esquecer a sua mágoa

Que traz os seus olhos, rasos d'água

A vida nesse mundo só nos dá prazer

$\mathrm{Eu}$ fico muito triste em lhe ver sofrer

Você é a alegria do meu lar

Volta novamente, vem cantar, ah, meu bem

"A maioria dos Sambas vai tudo embora, porque a gente esquece", admite Casquinha, um dos integrantes da Velha Guarda, mais adiante. A temática lírica, romântica, passional, no entanto, é uma constante impossível de não ser percebida. $O$ mistério do Samba explora como nenhum outro essa relação entre criador e criatura, ou melhor, entre o sambista e a mulher amada. "O fraco do homem é a mulher", Jair do Cavaquinho, sobre a maior inspiração que pode ter. "Tudo que fala em separação sou eu", Argemiro, lembrando que parte dessas composições também bebe do sofrimento. "Eu era muito devasso. Mas era forçado a ser devasso", o próprio Casquinha, sem esquecer que esse sofrimento pode ser consequência do comportamento do próprio compositor. Às mulheres, contudo, não cabe o eu-lírico. Marisa Monte percebe uma exceção em Você me abandonou, cuja letra discorre sobre uma mulher que não vai chorar, mas se vingar. "As mulheres não compunham, né?". O questionamento da mediadora busca delimitar a função de cada gênero na Velha Guarda. A escrita é masculina. A inspiração é feminina. As mulheres podem ainda atuar como pastoras, acompanhando as apresentações musicais como backing vocals, e organizadoras eventos, da cozinha à quadra. A conversa de Marisa Monte com Tia Doca, Tia Eunica, Tia Surica e Áurea Maria, atuais pastoras, por exemplo, acontece em um salão de beleza. Um território feminino, aos olhos da Por- 
tela/O mistério do Samba. Uma mise-en-scène que parece sublinhar o espaço de cada sexo. Por outro lado, o documentário não disfarça o quê machista que invariavelmente salta dessa disposição de posições. Zeca Pagodinho, portelense ilustre, faz questão de contar uma típica anedota sobre Argemiro, já falecido no ano da filmagem. "Foi o velho mais safado que eu já conheci". Um dia, o cantor, acompanhado de duas mulheres, fez uma visita ao sambista em sua casa em Oswaldo Cruz. Compraram cerveja, carne, salada. As mulheres cozinhando, "dando comida na boca do Argemiro". Na hora de ir embora, reconta Zeca Pagodinho, o portelense teria dito: "Vai embora, não! Manda essas piranhas lavar a louça”. O clima é descontraído. Quem ouve a história ri. Mas o subtexto se constrange.

Cartola corrobora o lirismo presente na maior parte das composições da Velha Guarda da Portela. Não à toa, o documentário explora em números musicais a onipresença radiofônica do mangueirense. Acontece, Alegria, As rosas não falam, Autonomia, Corra e olhe o céu, O mundo é um moinho, O sol nascerá, Quem me vê sorrindo, Tempos idos e Tive sim são algumas das gravações que ganham destaque no filme de Ferreira e Lacerda. Integram o repertório do Samba por excelência. Temos acesso a essas e outras performances por meio de imagens de arquivo, uma porcentagem razoável extraída do Brasil Especial Cartola, programa exibido pela TV Globo no ano de 1977. A participação do sambista no longa-metragem Ganga Zumba (1964), importante contribuição do cineasta Cacá Diegues ao Cinema Novo, é outro recurso imagético do qual se lança mão. Na ficção, além de Cartola, sua esposa, Dona Zica da Mangueira, também participa. Recorrendo à supracitada inventividade, a cena da morte de seu personagem é escolhida para ilustrar um momento difícil na trajetória do artista: o Zicartola, restaurante e casa de show sob administração do casal, está fechando as portas; as dívidas, por consequência, se alastram; e ambos se veem obrigados a voltar a morar na casa do pai do cantor. O ano é 1965. Efervescente ano, Cartola sabe disso. Sendo assim, sai costurando referências entrecruzadas: o canto de Os Mutantes, o encontro do Rei Pelé com o Rei Roberto Carlos, o casal 20 Leila Diniz e Domingos de Oliveira, Paulo Autran como Porfírio Diniz em Terra em transe (1967), de Glauber Rocha, o Rio de Janeiro dos Anos Dourados. Antes de se despedir, temos, portanto, mais uma amostra do poder de fogo do documentário: é a vida e a obra de Cartola, mas é também um pouco da vida e da obra do Brasil.

\section{Considerações finais}

Embora tenhamos dividido a análise sobre Onde a coruja dorme, Cartola - Música para os olhos e O mistério do Samba em três seções distintas, o 
Bezerra da Silva, Cartola \& Velha Guarda da Portela: um mergulho no documentário brasileiro contemporâneo sobre samba

entrecruzamento de seus personagens, temáticas e informações não se limita a esse enquadramento. Tamanho é o imbricamento entre esses registros audiovisuais que o diálogo gerado é uma constante. Não sem razão. Os três filmes se debruçam sobre figuras ilustres do universo do Samba, mas parecem à procura de apontamentos maiores sobre aquele universo. Do ponto de vista formal, podemos sugerir uma estrutura narrativa similar entre eles (entrevistas, imagens de arquivo, número musicais), mas o viés discursivo nos parece mais contundente.

Ao mobilizarmos autores como Felipe Trotta (2011), Carlos Sandroni (2001) e Hermano Vianna (2010), por exemplo, propúnhamos um mergulho no audiovisual tendo como guia teóricos preocupados com a história do gênero musical e com a representação (aqui, cinematográfica) dessa história. Quase um século após o surgimento do Samba urbano no Rio de Janeiro, esses documentários ainda suscitam debates em consonância com os debates trazidos à tona nos anos 1920 e 1930. De certa forma, nos faz pensar em como o Samba, ainda que pertencente a um panteão musical, segue se equilibrando entre a margem e o centro, o escamoteamento e a ode. Agora, exposto não apenas em som, mas também em imagem, por esses e outros documentários contemporâneos brasileiros.

\section{Referências bibliográficas}

Lins, C. \& Mesquita, C. (2011). Filmar o real: sobre o documentário brasileiro contemporâneo. Rio de Janeiro: Zahar.

Lopes, N. (2008). Partido-alto: samba de bamba. Rio de Janeiro: Pallas.

Marisa Monte. (s.d.). Velha guarda da Portela - tudo azul. Disponível em: www.marisamonte.com.br/pt/musica/producoes/velha-guarda-da-portela -tudo-azul

Sandroni, C. (2001). textitFeitiço decente: transformações do samba no Rio de Janeiro (1917-1933). Rio de Janeiro: Zahar: Editora UFRJ.

Trotta, F. (2011). textitO Samba e suas fronteiras: "pagode romântico" e "samba de raiz" nos anos 1990. Rio de Janeiro: Editora UFRJ.

Vargens, J. B. \& Monte, C. (2004). textitA velha guarda da Portela. Rio de Janeiro: Manati.

Vianna, H. (2010). textitO mistério do samba. Rio de Janeiro: Zahar: Editora UFRJ.

Vianna, L. F. (s.d.). textitSamba na veia. Folha de S. Paulo, São Paulo, 6 abr. 2007. Disponível em: www1.folha.uol.com.br/fsp/ilustrad/fq060420070 7.htm 


\section{Filmografia}

Brás Cubas (1985), de Júlio Bressane.

Cartola - Música para os olhos (2006), de Lírio Ferreira e Hilton Lacerda.

O mistério do Samba (2008), de Carolina Jabor e Lula Buarque de Hollanda.

Onde a coruja dorme (2012), de Márcia Derraik e Simplício Neto.

O que foi o carnaval de 1920? (1920), de Alberto Botelho.

Rio Zona Norte (1957), de Nelson Pereira dos Santos.

Terra em transe (1967), de Glauber Rocha.

Esse é um filme que nasce, evidentemente, de uma dor quase inominável, de uma tragédia, e, portanto, de uma falta, de uma cisão no real, de uma coisa que falta ser simbolizada para ser tolerável, e o que o filme faz é dar nome a essa coisa, organizar essa dor e torná-la, portanto, eu não diria tolerável, mas, é possível incorporá-la e seguir adiante na vida. ${ }^{1}$ 